\title{
Modification of 3'-AMP Forming Enzyme Activity by a Potent Immunosuppressant, ISP-I/Myriocin, in Liver of Mice Treated with Carbon Tetrachloride
}

\author{
Hiroyuki Fujimori,* Tetsuro Fujita, and Hidemitsu Pan-Hou \\ Faculty of Pharmaceutical Sciences, Setsunan University, 45-1 Nagaotoge-cho, Hirakata, Osaka 573-0101, Japan
}

(Received January 22, 2001; Accepted February 1, 2001)

The effect of ISP-I/myriocin on adenosine $\mathbf{3}^{\prime}$ monophosphate ( $3^{\prime}$-AMP) forming enzyme activity in carbon tetrachloride $\left(\mathrm{CCl}_{4}\right)$-induced hepatitis was examined. The 3 '-AMP forming enzyme activity in mouse liver was enhanced by the treatment of $\mathrm{CCl}_{4}$. The increase in the activity in cytosol may result from the leakage of the enzyme from mitochondria via the damage of mitochondrial membrane induced by $\mathrm{CCl}_{4}$. Pretreatment of mice with ISP-I/myriocin for $24 \mathrm{hr}$, significantly inhibited both the $\mathrm{CCl}_{4}$-induced activities of serum alanine aminotransferase and the 3 '-AMP forming enzyme in the supernatant of liver homogenate prepared immediately after the organ excision. These results suggest that the inhibitory effects of ISP-I/ myriocin may be due to inhibition of lipid peroxidation of intracellular membranes caused by $\mathrm{CCl}_{4}$, in turn inhibiting the leakage of the $3^{\prime}$-AMP forming enzyme from mitochondria to cytosol. Our results demonstrated for the first time that ISP-I/myriocin has a protective effect on the $\mathrm{CCl}_{4}$-induced hepatotoxicity.

Key words — adenosine 3 '-monophosphate forming enzyme, ISP-I/myriocin, carbon tetrachloride, adenosine 3'-monophosphate, mouse liver

\section{INTRODUCTION}

Adenylate cyclase is known to be regulated by a number of extracellular and intracellular signals. Intracellular adenosine 3'-monophosphate (3'-AMP), one of the degradation products of RNAs, has been pharmacologically classified as a P-site inhibitor of adenylate cyclase. ${ }^{1)}$ The $3^{\prime}$-AMP forming enzyme, one of the ribonucleases, has been shown to exist not only in homogenates of various organs in rat $^{2)}$

\footnotetext{
*To whom correspondence should be addressed: Faculty of Pharmaceutical Sciences, Setsunan University, 45-1 Nagaotoge-cho, Hirakata, Osaka 573-0101, Japan. Tel. \& Fax: +81-72-866-3159; E-mail: fujihiro@pharm.setsunan.ac.jp
}

but also in soluble fractions of rat liver mitochondria. ${ }^{3,4)}$ However, the physiological and pathophysiological roles of $3^{\prime}$-AMP and the $3^{\prime}$-AMP forming enzyme still remains to be elucidated.

Carbon tetrachloride $\left(\mathrm{CCl}_{4}\right)$ is widely accepted as a cause of hepatic necrosis and fatty liver. The toxicity of $\mathrm{CCl}_{4}$ is mediated by a highly reactive trichloromethyl radical to produce lipid peroxides in the hepatocellular membranes. ${ }^{5}$ The damage of cellular membranes via lipid peroxidation results in leakage of intracellular enzymes, including cytosolic, mitochondrial and lysosomal enzymes. Therefore, $\mathrm{CCl}_{4}$ may serve as a tool for studying the pathophysiological roles of the $3^{\prime}$-AMP forming enzyme in mitochondria.

ISP-I/myriocin, as a potent immunosuppressant, was found to inhibit allo-reactive cytotoxic T lymphocyte generation $^{6)}$ and induce apoptosis of an IL2-dependent cytotoxic T cell line, CTLL-2. ${ }^{7)}$ The ISP-I/myriocin-induced apoptosis is probably triggered by the inhibition of serine palmitoyltransferase, which catalyzes the first step of sphingosine biosynthesis, and the condensation of serine and palmitoyl-CoA. ${ }^{8)}$ Palmitoyl-CoA is also a substrate for carnitine palmitoyltransferase I, which facilitates passsage of long-chain fatty acids into mitochondria for $\beta$-oxidation. ${ }^{9)}$ When the biosynthetic pathway of sphingolipids were inhibited by ISP-I/myriocin, the activity of the $3^{\prime}$-AMP forming enzyme in mitochondria might be influenced and the effect of $\mathrm{CCl}_{4}$ on membrane lipid peroxidation of mitochondria might be modified.

Recently, our preliminary results revealed that the activity of the $3^{\prime}$-AMP forming enzyme was influenced by $\mathrm{CCl}_{4}$. In the present study, we examined the effect of ISP-I/myriocin on the activity of the 3 -AMP forming enzyme in the situation of hepatitis induced by $\mathrm{CCl}_{4}$. We found that ISP-I/myriocin modified $\mathrm{CCl}_{4}$ induced both the activities of the $3^{\prime}$ AMP forming enzyme and serum alanine amino- 
transferase (ALT).

\section{MATERIALS AND METHODS}

Materials — ISP-I/myriocin was obtained as described previously ${ }^{6}$ and stored as a methanol solution at $-20^{\circ} \mathrm{C} . \mathrm{CCl}_{4}$, olive oil, chloroacetaldehyde and the glutamic-pyruvic transaminase-ultraviolet (GPT-UV) test kit Wako were purchased from Wako Pure Chemicals Co. (Osaka, Japan). Poly(A) and 3'AMP were from Yamasa Shouyu Co. (Chiba, Japan). A high performance liquid chromatography (HPLC) column $(150 \times 4.6 \mathrm{~mm}$ i.d. $)$ of Chromatorex ODS (DU0005MTP, $5 \mu \mathrm{m}$ ) was kindly supplied by Fuji Silysia Chemical, Ltd. (Aichi, Japan). Other chemicals of reagent grade were commercially obtained. Male ICR strain mouse ( 3 weeks old) were obtained from Charls River Japan, Inc. (Hino, Japan).

Treatment of Mice with ISP-I and $\mathbf{C C l}_{4}-$ In all experiments, food and water were available $a d$ libitum. ISP-I $(0.1 \% \mathrm{w} / \mathrm{v})$ dissolved in methanol was diluted with olive oil to make the final concentration of $0.0025 \%(\mathrm{w} / \mathrm{v})$. The diluted ISP-I or vehicle (olive oil) was intraperitoneally given to mice at a dose of $4.0 \mathrm{ml} / \mathrm{kg}$ body weight. At $24 \mathrm{hr}$ after ISP-I or vehicle administration, $10 \%(\mathrm{v} / \mathrm{v}) \mathrm{CCl}_{4}$ dissolved in olive oil or vehicle was intraperitoneally injected at a dose of $4.0 \mathrm{ml} / \mathrm{kg}$ body weight. At $24 \mathrm{hr}$ after $\mathrm{CCl}_{4}$ administration, blood was withdrawn from the abdominal aorta under diethyl ether anesthesia, and the serum was prepared. The activity of ALT in the serum was measured using a GPT-UV-test kit Wako. Preparation of Liver Homogenate — The liver obtained from ISP-I or $\mathrm{CCl}_{4}$-treated mice was removed rapidly and weighed. The liver $(1 \mathrm{~g})$ was homogenized immediately after removal in $19 \mathrm{ml}$ of $1 \mathrm{mM}$ EDTA, $0.25 \mathrm{M}$ sucrose and $5 \mathrm{mM} 2-$ mercaptoethanol containing $20 \mathrm{mM}$ Tris/HCl buffer, $\mathrm{pH}$ 7.5. The homogenate was centrifuged at $18000 \times g$ for $15 \mathrm{~min}$. The supernatant obtained was kept at $-80^{\circ} \mathrm{C}$ until use, and used as a crude enzyme solution.

Determination of $3^{\prime}$-AMP Forming Enzyme Activity — 3'-AMP forming enzyme activity was determined as follows. The reaction mixture $(55 \mu \mathrm{l})$ consisted of $20 \mathrm{mM}$ EDTA containing $0.1 \mathrm{M}$ acetate buffer (pH 5.6), $25 \mu \mathrm{g}$ poly(A) and $5 \mu \mathrm{l}$ of the crude enzyme solution. After incubation of the mixture at $37^{\circ} \mathrm{C}$ for $60 \mathrm{~min}$, the reaction was terminated by the addition of $55 \mu \mathrm{l}$ of $15 \mathrm{mM} \mathrm{ZnCl}_{2}$ in $0.5 \mathrm{M}$ perchloric acid. The enzymic products were derivatized with chloroacetaldehyde for fluorescence detection. ${ }^{10)}$ The derivatized compounds were analyzed by a reversedphase HPLC using a column of Chromatorex ODS maintained at $45^{\circ} \mathrm{C}^{4)}$

\section{RESULTS AND DISCUSSION}

The histochemical localization of the $3^{\prime}$-AMP forming enzyme has not yet been clarified, but its enzymic activity has been confirmed to exist, at least in hepatic mitochondria. ${ }^{4)}$ The enhancement of the activity of the 3'-AMP forming enzyme in cytosol may be due to the leakage of the activity from mitochondria and other subcellular organelles in impaired cells. There is no report mentioning the change of $3^{\prime}$-AMP forming enzyme activity in the pathophysiological situation. It is of interest to examine whether or not $\mathrm{CCl}_{4}$ could affect $3^{\prime}$-AMP forming enzyme activity in acute hepatitis.

As shown in Table 1, serum ALT activity was greatly enhanced $24 \mathrm{hr}$ after $\mathrm{CCl}_{4}$ administration. Under these situations, the activity of the $3^{\prime}$-AMP forming enzyme in the supernatant of homogenate obtained from fresh liver was increased by $\mathrm{CCl}_{4}$ administration. These results suggest that leakage of the activity from mitochondria to cytosol might be enhanced by the damage of mitochondrial membranes via lipid peroxidation induced by $\mathrm{CCl}_{4}$. The increase in 3'-AMP forming enzyme activity might contribute to the RNA metabolism involving the elimination of RNAs in impaired hepatocytes, and the turnover of RNAs in regenerative or repaired hepatocytes. At present we do not have enough information to warrant further discussion on this phenomena. The detailed pathophysiological significance of this enzyme remains to be elucidated.

Fujita et $_{\text {al }}{ }^{6)}$ reported that allo-reactive cytotoxic $\mathrm{T}$ lymphocyte generation in BALB/c mice was inhibited by ISP-I/myriocin, intraperitoneally administered in the range of 0.01 to $1.0 \mathrm{mg} / \mathrm{kg}$ body weight. The growth of the cytotoxic T-cell line in mice, CTLL-2, was also inhibited, ${ }^{8)}$ and the cell death by

Table 1. Effect of $\mathrm{CCl}_{4}$ on the Activities of Serum ALT and the 3'-AMP Forming Enzyme in Mouse Liver

\begin{tabular}{ccc}
\hline \hline Treatment & ALT & $\begin{array}{c}3^{\prime} \text {-AMP forming enzyme } \\
\text { IUmol/mg }\end{array}$ \\
\hline None & $100 \pm 8$ & $0.45 \pm 0.07$ \\
$\mathrm{CCl}_{4}$ & $4500 \pm 399$ & $0.71 \pm 0.04 *$ \\
\hline Each value & represents the mean \pm S.E. of five animals. \\
$*$ Significantly different from control group $(p<0.01)$.
\end{tabular}


apoptosis was enhanced by the addition of ISP-I/ myriocin to the culture medium in an in vitro experiment. ${ }^{7)}$ Interestingly, ISP-I/myriocin-induced apoptosis was delayed, requiring more than $32 \mathrm{hr}$ to occur, following one or more cell divisions. ${ }^{7)}$ As ISP$\mathrm{I} /$ myriocin might affect sphingolipid metabolism in a number of cells other than CTLL-2 via the inhibition of a serine palmitoyltransferase, the compound might have some influences on hepatic functions in acute hepatitis induced by $\mathrm{CCl}_{4}$. Taking these results reported and our speculation into consideration, the effect of $24 \mathrm{hr}$-pretreatment of mice with ISP-I/ myriocin on $\mathrm{CCl}_{4}$-induced acute hepatotoxicity was examined at a dose of $0.1 \mathrm{mg}$ ISP-I/myriocin per $\mathrm{kg}$ body weight under the experimental condition described in Method. Pretreatment of mice with ISP-I/ myriocin significantly inhibited the $\mathrm{CCl}_{4}$-induced increase in the activities of serum ALT and the 3'AMP forming enzyme as shown in Fig. 1-(A) and 1-(B), respectively. Simultaneous administration of $\mathrm{CCl}_{4}$ and ISP-I/myriocin was less effective in decreasing $\mathrm{CCl}_{4}$-induced enhancement of both activities [Fig. 1-(A) and 1-(B)]. Single administration of ISP-I/myriocin had no significant effect on 3'-AMP forming enzyme activity at 24 and $48 \mathrm{hr}$ after its administration (data not shown). These results suggested that ISP-I/myriocin might suppress the leakage of the activity of the $3^{\prime}$-AMP forming enzyme, at least from mitochondria, due to the inhibition of the damage of intracellular membranes by the $\mathrm{CCl}_{4}{ }^{-}$ induced lipid peroxidation, and could modify the activity of the $3^{\prime}$-AMP forming enzyme in acute hepatitis induced by $\mathrm{CCl}_{4}$. To our knowledge, this is the first paper describing that ISP-I/myriocin might have a protective effect on the $\mathrm{CCl}_{4}$-induced hepatotoxicity.

$3^{\prime}$-AMP is known to be classified as a P-site inhibitor of membrane-bound adenylate cyclase. ${ }^{1)}$ Bushfield et $a{ }^{2}{ }^{2)}$ reported that streptozotocin-induced enhancement of $3^{\prime}$-AMP contents in rat liver was reversed by insulin treatment. Together, this finding with our results obtained in the present study, suggested that the activity of the 3'-AMP forming enzyme could be affected by changes in pathophysiological circumstances. The formation and accumulation of $3^{\prime}$-AMP by the activation of the $3^{\prime}$-AMP forming enzyme may affect cell functions via the inhibition of adenylate cyclase and AMP-dependent enzymic reactions. Clearly, further work is needed to understand the physiological and pathophysiological roles of the $3^{\prime}$-AMP forming enzyme.
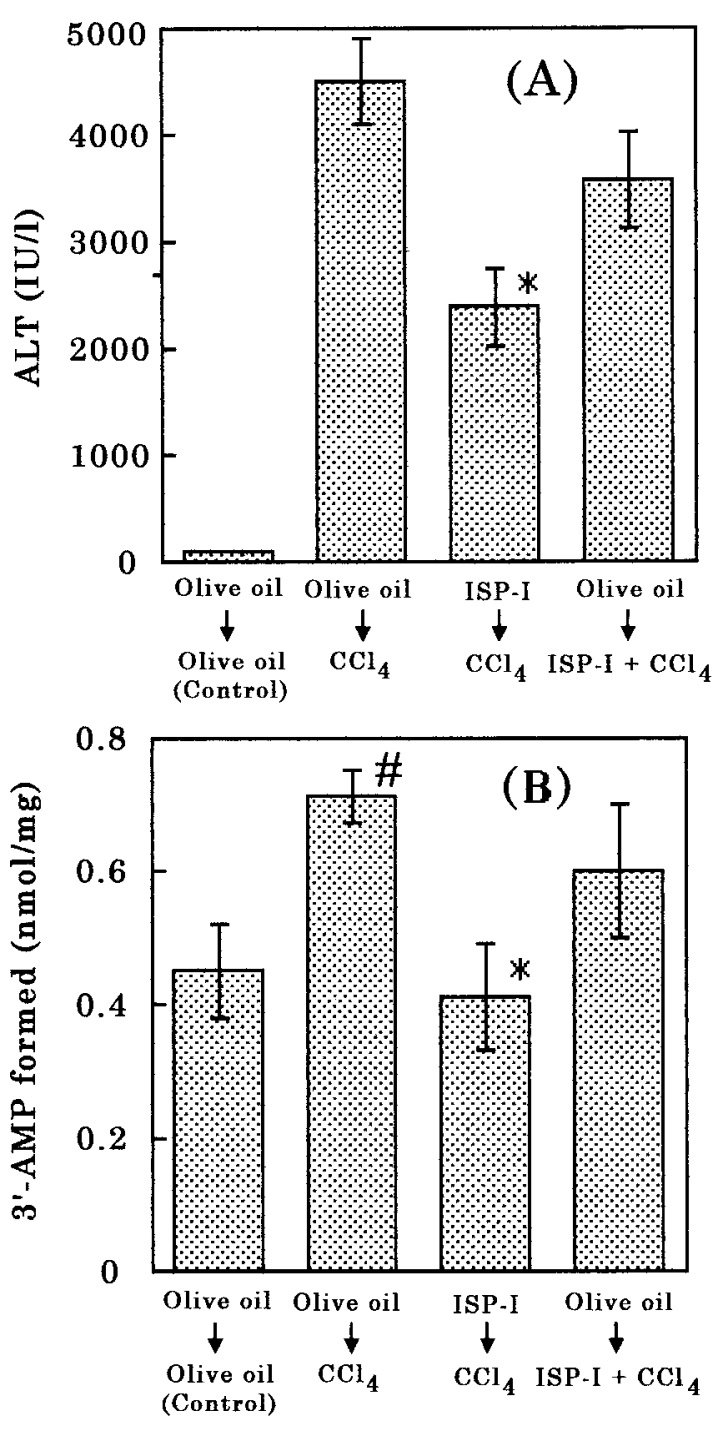

Fig. 1. Inhibitory Effect of ISP-I/Myriocin on $\mathrm{CCl}_{4}$-Induced Enhancement of Activities of Serum ALT (A) and 3'AMP Forming Enzyme in Mouse Liver (B)

Each value represents the mean \pm S.E. of five animals. \#Significantly different from control group $(p<0.01)$. *Significantly different from the $\mathrm{CCl}_{4}$-treated group $(p<0.01)$.

Acknowledgements The authors are grateful to Mr. T. Hirooka, Miss R. Sato, Miss M. Hiraoka, and Mr. J. Okada of this University for their technical assistance.

\section{REFERENCES}

1) Johnson, R. A., Yeung, S. H., Stubner, D., Bushfield, M. and Shoshani, I. (1989) Cation and Structural Requirements for P Site-mediated Inhibition of Adenylate Cyclase. Mol. Pharmacol., 35, 681-688.

2) Bushfield, M., Shoshani, I. and Johnson, R. A. 
(1990) Tissue Levels, Source, and Regulation of 3'AMP: An intracellular Inhibitor of Adenylyl Cyclases. Mol. Pharmacol., 38, 848-853.

3) Fujimori, H. and Pan-Hou, H. (1998) Formation of Adenosine 3'-Monophosphate in Rat Liver Mitochondria. Biol. Pharm. Bull., 21, 624-627.

4) Fujimori, H., Sato, R., Yasuda, M. and Pan-Hou, H. (1998) A Specific and Rapid Method for Determination of Adenosine 3'-Monophosphate (3'AMP) Content and 3'-AMP Forming Enzyme Activity in Rat Liver Mitochondria, Using Reversedphase HPLC with Fluorescence Detection. Biol. Pharm. Bull., 21, 1348-1351.

5) Poli, G., Albano, E. and Dianzani, M. U. (1987) The Role of Lipid Peroxidation in Liver Damage. Chem. Phys. Lipids, 45, 117-142.

6) Fujita, T., Inoue, K., Yamamoto, S., Ikumoto, T., Sasaki, S., Toyama, R., Yoneta, M., Hoshino, Y. and Okumoto, T. (1994) Fungal Metabolites. Part 11. A Potent Immunosuppressive Activity Found in Isaria sinclairii Metabolite. J. Antibiot., 47, 208-215.

7) Nakamura, S., Kozutsumi, Y., Sun, Y., Miyake, Y., Fujita, T. and Kawasaki, T. (1996) Dual Roles of Sphingolipids in Signaling of the Escape from and Onset of Apoptosis in a Mouse Cytotoxic T-cell Line, CTLL-2. J. Biol. Chem., 271, 1255-1257.

8) Miyake, Y., Kozutsumi, Y., Nakamura, S., Fujita, T. and Kawasaki, T. (1995) Serine Palmitoyltransferase is the Primary Target of a Sphingosine-like Immunosuppressant, ISP-I/myriocin. Biochem. Biophys. Res. Commun., 211, 396-403.

9) McGarry, J. D., Woeltje, K. F., Kuwajima, M. and Foster, D. W. (1989) Regulation of Ketogenesis and the Renaissance of Carnitine Palmitoyltransferase. Diabetes Metab. Rev., 5, 271-284.

10) Fujimori, H., Yamauchi, M. and Pan-Hou, H. (1991) Availability of Chloroacetaldehyde as a Fluorescent Reagent for a Determination of Adenine Compounds by a High-performance Liquid Chromatography. Chem. Express, 6, 715-718. 